\title{
Growth Efficiency and Carbon Balance for the Sponge Haliclona oculata
}

\author{
Marieke Koopmans • Dirk Martens • Rene H. Wijffels
}

Received: 19 January 2009 / Accepted: 30 July 2009/Published online: 1 October 2009

(C) The Author(s) 2009. This article is published with open access at Springerlink.com

\begin{abstract}
To obtain more knowledge about carbon requirements for growth by sponges, the growth rate, respiration rate, and clearance rate was measured in situ in Haliclona oculata. We found that only $34 \%$ of the particulate carbon pumped through the sponge was used for both respiration and growth. The net growth efficiency, being the ratio of carbon incorporated in biomass and the total carbon used by the sponge for respiration and growth, was found to be $0.099 \pm 0.013$. Thus, about $10 \%$ of the total used carbon was fixed in biomass, and over $90 \%$ was used for generating energy for growth, maintenance, reproduction, and pumping. H. oculata had $2.5 \mu \mathrm{mol} \mathrm{C}$ available for every micromole $\mathrm{O}_{2}$ consumed. A value of 0.75 for respiratory quotient (RQ in micromole $\mathrm{CO}_{2}$ micromole $\mathrm{O}_{2}^{-1}$ ) was used for $H$. oculata, which is the average value reported in literature for different marine invertebrates. Thus, carbon was available in excess to meet the respiratory demand. Oxygen was found not to be the limiting factor for growth, since only $3.3 \%$ of the oxygen pumped through the sponge body was used. Our results indicate that both oxygen and carbon availability are not limiting. The low growth efficiency agrees with the low growth rates found for the species used in this study.
\end{abstract}

Keywords Sponge $\cdot$ Haliclona oculata $\cdot$ Clearance rate .

Respiration · Growth efficiency · Carbon balance

\section{Introduction}

Sponges are potential producers of pharmaceutical compounds due to their rich variety of bioactive metabolites. In

M. Koopmans $(\bowtie) \cdot$ D. Martens $\cdot$ R. H. Wijffels Department of Agrotechnology and Food Sciences, Bioprocess Engineering Group, Wageningen University, P.O. Box 8129, 6700 EV Wageningen, The Netherlands e-mail: Marieke.Koopmans@wur.nl order to obtain sufficient amounts of bioactive compounds, a sustainable production technique is required. Culturing sponges ex situ would be an interesting option, if we can stimulate sponge growth. Many growth studies showed that sponges are slow growing organisms (e.g., Dayton 1979; Garrabou and Zabala 2001; Duckworth and Pomponi 2005; de Caralt et al. 2007; Koopmans and Wijffels 2008). Specific growth rates have been measured between 0.006 and 0.05 per day. In many studies, seasonal variation in growth is found (e.g., Barthel 1986; Garrabou and Zabala 2001; Page et al. 2005; Koopmans and Wijffels 2008), with lower growth rates generally being measured in winter. Plausible explanations for the lower growth in winter could be lower availability of food, hence less uptake of energy, while lower temperature causes lower metabolic rate. There have been a few successes in ex situ sponge cultivation (Duckworth et al. 2003; Page et al. 2005). However, there number is very limited. Consequently, sustainable production methods have not been attained yet. To improve the growth of sponges, basic knowledge on how they acquire and use their food is necessary. Therefore, we studied the carbon balance and growth efficiency for Haliclona oculata in the Oosterschelde, The Netherlands.

Sponges mainly feed by filtering particles from the large amounts of water that they pump through their body. Many studies have focused on the filtering capacity of sponges (Riisgård et al. 1993; Ribes et al. 1999; Lynch and Phlips 2000; Stabili et al. 2006; de Goeij et al. 2008a). It was shown that they can filter up to 72,000 times their body volume per day. Particle retention efficiencies are found to be very high up to $58-99 \%$ (Pile et al. 1997), 86\%, (Duckworth et al. 2006) and 96.1\% for bacterial uptake in three species of sponges (Reiswig 1971). Besides filtering particles, sponges are also able to obtain food particles through the external epithelia cells, via phagocytosis, and sponges containing symbiotic bacteria can obtain nutrients via these symbionts. In addition, it was shown that some 
sponges can assimilate dissolved organic material (de Goeij et al. 2008b).

The retained food is used for two purposes, being to supply nutrients for sponge biomass and to supply energy in which case the carbon is converted to carbon dioxide, which is assumed to take place via aerobic metabolism. From the oxygen available in the water, maximally $10 \%$ is taken up by sponges (Jorgensen et al. 1986). The amount of carbon needed for respiration can be calculated using the respiratory quotient (RQ). The respiratory quotient is the ratio between $\mathrm{CO}_{2}$ produced and $\mathrm{O}_{2}$ consumed. Depending on which carbon compound is used as a food source for oxidation, the ratio varies from 0.7 (lipid oxidation) to 1.0 (carbohydrate oxidation). Consequently, RQ values vary depending on organism and used food source. Not many studies have focused on the respiratory quotient for marine invertebrates and sponges in general. An average RQ value of 0.75 was found for four different marine invertebrates by Hatcher (1989), namely for a bryozoan, an ascidian, a chiton, and an abalone species. In other comparable studies, an RQ value of 0.69 was found for cephalopoda (BoucherRodoni and Boucher 1993) and 0.74 for ophiurid (Migne and Davoult 1997). An RQ of 0.75 means that for every mole of oxygen, $0.75 \mathrm{~mol}$ of carbon is converted to carbon dioxide. This low value indicates that lipids are probably a large fraction of the compounds used for oxidation by marine invertebrates. This agrees with the fact that most invertebrates feed on particulate organic matter including algae (Reiswig 1971; Mohlenberg and Riisgard 1978), which can accumulate lipids up to $50 \%$ of their dry weight (Collyer and Fogg 1954; Hu et al. 2008).

The obtained energy is used in different processes in the sponge being for pumping, maintenance, reproduction, and growth. The fraction of the total amount of metabolized carbon that is incorporated into biomass is called the net growth efficiency (NGE). Thus, a higher NGE means that a relatively high amount of carbon is fixed into biomass of the assimilated carbon. Thomassen and Riisgård (1995) found that NGE is positively related to the specific growth rate. At a growth rate of $4 \%$ per day, they found a NGE of 30 , and at $1 \%$ per day, it was about 10 . Thus, higher growth rates give a higher net growth efficiency. The total rate with which carbon is metabolized is the sum of the incorporation rate in biomass (growth) and the rate of carbon liberated as carbon dioxide (respiration). The NGE can be calculated using the next equation (adjusted from Thomassen and Riisgård 1995):

$\mathrm{NGE}=\frac{\mu \cdot C^{\mathrm{x}}}{\mu \cdot C^{\mathrm{x}}+\mathrm{RQ} \cdot R}$

where $C^{\mathrm{x}}$ is the carbon content (micromole $\mathrm{C}$.per gram dry weight $(\mathrm{dw})), \mu$ the growth rate (per day), RQ the respiratory quotient (micromole $\mathrm{C} \cdot$ micromole $\mathrm{O}_{2}$ ), and $R$ is the specific oxygen consumption rate (micromole $\mathrm{O}_{2}$.per gram $\mathrm{dw}$ per day).

The amount of carbon taken up by the sponge can be calculated using the clearance rate multiplied by particulate organic carbon (POC). In our former publication (Koopmans and Wijffels 2008), we showed that $H$. oculata has a seasonal trend with respect to growth rate. We showed that there is a strong correlation of growth rate with POC and no correlation with dissolved organic carbon (DOC), suggesting that growth of this sponge is more dependent on available POC.

To obtain more insight in the carbon usage of sponges in relation to energy and biomass increase, the growth rate, respiration rate, and clearance rate were measured in situ for the sponge $H$. oculata. The growth rate was reported in previous work (Koopmans and Wijffels 2008). The combination of these three factors has not been studied much. A carbon balance is made to find if all available carbon is used efficiently by the sponge for growth. Clearance efficiency and net growth efficiency were calculated and compared with other sponges. Thus, we want to obtain more insight in how sponges acquire and use their food, which in future may allow improvement of the sponge growth rate.

\section{Materials and Methods}

\section{Study Area}

Measurements were done in situ in the Netherlands, Oosterschelde estuary (Lokkersnol, 51 ${ }^{\circ} 38^{\prime} 58.07^{\prime \prime} \mathrm{N}, 3^{\circ} 53^{\prime}$ $\left.5.11^{\prime \prime} \mathrm{E}\right)$ at $13 \mathrm{~m}$ depth at low tide. The sponge species used was $H$. oculata. This sponge widely occurs in the Oosterschelde and grows attached to solid surfaces such as oyster shells. A platform was placed at the study site, and 42 concrete pavement tiles $(30 \mathrm{~cm} \times 30 \mathrm{~cm})$ were placed on top of the platform. On every tile, a sponge specimen was attached. For 11 specimens, the growth rate was monitored for 1 year (Koopmans and Wijffels 2008). Due to dive time limitation, only three sponge individuals were used for the results presented here. Attachment of the sponge specimens used in the growth study, which were the same specimens used in this study, was done in August 2005. Attaching was done by using elastic bands keeping the sponges against the tiles. Within 1 month, all sponges were attached to the tiles on the platform, and they were fully healed when we performed our experiments. The respiration and clearance rates experiments were performed in summer 2006.

\section{Respiration Rate}

Respiration rates were measured both in situ for three individuals and in the laboratory for three individuals. 
Laboratory experiments were done in the same period as the in situ experiments were done. Laboratory experiments were done to find out if the in situ measured values coincide with values measured using more controllable equipment in the laboratory.

For the in situ experiments, experimental chambers, made of polyvinylchloride with $765 \mathrm{~mL}$ volume, were developed. The chamber had an opening underneath to completely cover the sponge. The chamber was placed over the sponge, and by using elastic bands, the chamber could easily be attached to the tiles. Two different chambers were made: one to connect an oxygen probe and one containing a small sampling tube for taking water samples. A magnetic stirrer inside the chamber continuously mixed the water inside to prevent particles from settling and to equalize oxygen distribution. $\mathrm{O}_{2}$ concentrations were measured using two Oxi 340i handheld oxygen meters (WTW, Weilheim, Germany). The oxygen concentration inside a chamber was logged every $10 \mathrm{~s}$. The meter connected to the probe was in a waterproof box and taken underwater. Experiments lasted for $15 \mathrm{~min}$, to minimize the effect of oxygen depletion. Five measurements were done for every individual over a period of 4 weeks in July and August 2006. Blank (control) measurements were done simultaneously, to see if oxygen concentration stayed constant, by using an empty tile on the platform.

In the laboratory, glass chambers of $450 \mathrm{~mL}$ volume were used for the respiration rate experiments. Three other sponge specimens were collected in the area where the in situ experiments were done. They were disconnected from their hard substrate and transported in a Styrofoam box to the university laboratory, which was a 2 -h drive. After collection, the aquiferous system was not damaged as these species have clear tissue which is attached, separate from the aquiferous system. There the sponges were kept in a 1,200-1 aquarium for acclimatization. The aquarium contained artificial seawater, using Instant Ocean Reef Crystals artificial sea salt, at a $\mathrm{pH}$ of 8.1 and the same temperature and salinity as in the natural environment. One day after collection, the sponges were introduced in the experimental glass chambers. Artificial seawater solutions in the chamber were stirred, and particles were kept in suspension using a magnet spun at a speed of $300 \mathrm{rpm}$. Custom made wire baskets prevented the sponges from touching the stirring mechanism. A blank (control) experiment was performed simultaneously, being an empty glass chamber. Per individual, five measurements were done by resaturating the seawater with air.

The oxygen concentration inside the chamber decreased linearly, where the slope of this decrease multiplied by the volume of the chamber is equal to the respiration rate (milligram $\mathrm{O}_{2}$ per minute) of the sponge. The specific respiration rate can then be determined by dividing the respiration rate by sponge dry weight, which was measured as described in previous work (Koopmans and Wijffels 2008).

\section{Clearance Rate}

The clearance rate is defined here as the amount of water pumped through the sponge body and cleared from cells. The population we have used for our calculation was cleared by the sponge with a $100 \%$ clearance efficiency. Clearance rates were only measured in situ for two individuals with five repetitive measurements per individual. The third specimen got detached from the platform before we finished the clearance rate experiment. After placement of the experimental chamber for measuring clearance rate, the first water sample of $10 \mathrm{~mL}$ was taken immediately using a syringe. Every $3 \mathrm{~min}$, water samples were taken, and the measurement lasted for $15 \mathrm{~min}$ in total, which made a total of six water samples per clearance rate measurement. Fifteen minutes was chosen as it showed to have a good and measurable result in both oxygen depletion and particle decrease. From the respiration measurements, we could see that there was no effect from oxygen depletion or excretion of waste by the sponge. Immediately after the performed experiments in situ, $5 \mathrm{~mL}$ of the water samples were fixed with glutaraldehyde ( $1 \%$ final concentration). Fixation lasted for $30 \mathrm{~min}$ in the dark, after which, the samples were stored in dry ice.

Particle count was performed with the CyAn ADP flow cytometer (Beckman Coulter, Miami, FL) equipped with a $50-\mathrm{mW}$ solid state laser at $488 \mathrm{~nm}$ and a $60-\mathrm{mW}$ diode laser at $642 \mathrm{~nm}$. Autofluorescent emission of the particles in the water sample was measured at different wavelengths ranging from 450 to $750 \mathrm{~nm}$. The clearest population was found at green fluorescence (FL1) at $530 \pm 40 \mathrm{~nm}$ and yellow fluorescence (FL2) at $575 \pm 25 \mathrm{~nm}$. Calibration prior to each analysis was done by measuring the fluorescent signal of $3.0 \mu \mathrm{m}$ SpectrAlign beads (Beckman Coulter, Miami, FL) exciting and emitting at 405 and $488 \mathrm{~nm}$, respectively, prior to utilization of the flow cytometer. The sample analysis time was $2 \mathrm{~min}$. The flow rate of the system was calibrated using fluorospheres with a diameter of $3 \mu \mathrm{m}$, at a concentration of 1.000 particles per microliter. The calibration was performed in triplicate for $2 \mathrm{~min}$ at different flow rates. Subsequently, the volume (microliters per minute) of each analyzed sample was calculated. An average flow rate of $65 \mu \mathrm{L}$ per minute was used as a standard value to calculate the concentration of particles present in each sample in further experiments. Clearance rates $(F)$ were determined based on the clearance of a single population that was $100 \%$ retained by the sponge using the formula:

$F=\frac{V}{t} * \ln \left(\frac{C_{0}}{C_{t}}\right)$ 
in which $V$ stands for volume of water (milliliter), $t$ is time (minute), and $C_{0}$ and $C_{t}$ are the concentration of counted particles per milliliter at time 0 and time $t$ (minute), respectively.

\section{POC Concentration}

Total POC was determined by measuring the total organic carbon content in the suspended organic matter. Water samples were filtered by using a GF/F filter $(0.7 \mu \mathrm{m})$ and suspended particulate matter (SPM) was determined by weighing. Total organic carbon was analyzed in SPM in a Carlo-Erba NA-1500 elemental analyzer according to Nieuwenhuize et al. (1994).

\section{Content and Dry Weight}

The carbon content of five whole sponges collected in the same period and in the same area as the used sponges for these experiments was measured after oven drying at $50^{\circ} \mathrm{C}$, using a Fisons NA 2500 element analyzer (serial number 991493), with autosampler and Haysep-Q column 80-100 mesh I.D. $2 \mathrm{~mm}$ (see also Nieuwenhuize et al. 1994). In short, the dried sample was combusted in an oxygen-rich environment at $1,010^{\circ} \mathrm{C}$. After drying, the formed $\mathrm{CO}_{2}$ and $\mathrm{N}_{2}$ are separated on a GC column and detected using a thermal conductivity detector. For the dry weight measurement, the sponges from the laboratory experiment were dried in a stove overnight at $80^{\circ} \mathrm{C}$, after which, dry weight was determined. The average measured carbon content was used in our further calculations.

\section{Carbon Assimilation}

The carbon assimilation rate was calculated by multiplying the carbon content by the specific growth rate. For the laboratory experiments, we used the average growth rate measured in summer to calculate carbon assimilation. The field experiments were always performed with the same individuals, and therefore, we used the specific growth rate per individual as presented in previous work (Koopmans and Wijffels 2008) for our calculations of carbon assimilation for the field experiments.

\section{Results}

Available Carbon

To study whether the availability of carbon could limit the growth of $\mathrm{H}$. oculata, we estimate the uptake of carbon from the POC and the clearance rate. Flow cytometry showed one separate population (Fig. 1) that was cleared with $100 \%$ retention efficiency. Figure 1 shows that not all particles of this population were retained at the end of the experiment. However, at the time of the measurement not all water was filtered by the sponge yet. Moreover, we found that the equation assuming $100 \%$ retention efficiency fitted the data significantly better than an equation assuming a lower efficiency. The population seems to be Synechococcus cyanobacteria as it shows the same signature as the Synechococcus cyanobacteria population shown in Moreira-Turcq and Martin (1998). Synechococcus has a size between 0.8 and $1.5 \mu \mathrm{m}$ and is highly retained up to $100 \%$ by other species of sponges as well (Ribes et al. 1999; Hadas et al. 2008). Thus, this population is well suited to be used for clearance rate calculations. Therefore, we have used this population for our clearance rate calculations assuming an exponential decrease (Eq. 2). We are conscious about the fact that more food particles are available to the sponge and that more will be used by the sponge. However, for calculating clearance rate one population is sufficient. Again, blank measurements were done simultaneously. Figure 2 shows the normalized average particle concentration of the specific population shown in Fig. 1 for the two used sponges and the blank
Fig. 1 Flow cytometer results of two water samples (without addition of calibration particles), yellow ( $y$-axis) versus green ( $x$-axis) fluorescence. Left figure shows cell count at $t=0$ and right figure at $t=15 \mathrm{~min}$. The boxes represent the population used for our clearance rate calculations
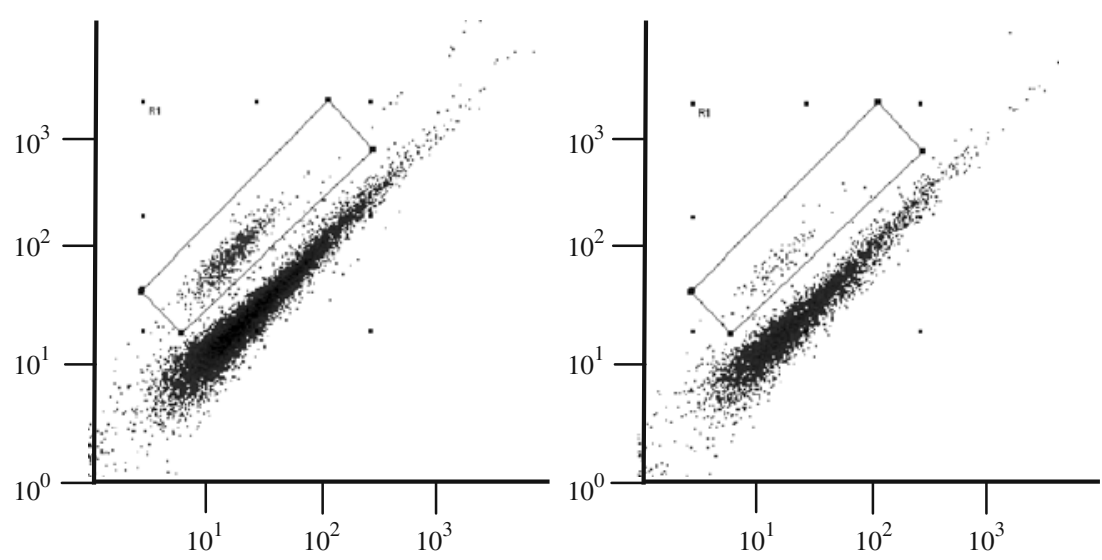


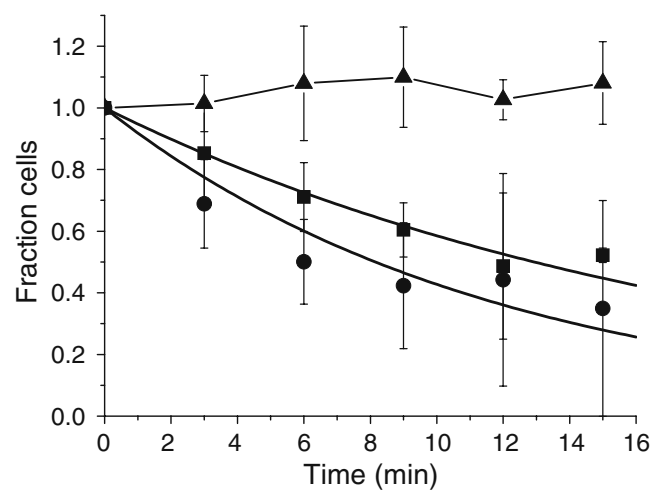

Fig. 2 Normalized concentration of counted Synechococcus cells at different time steps for sponge 1 (squares), sponge 2 (circles), and a blank measurement (triangles). The error bars show the standard deviation calculated from the replicates performed for one individual or blank. The lines show exponential regression lines for both sponges. The concentrations are normalized for the start concentration

experiments. The particle concentrations are normalized for the start concentration. The average Synechococcus cell

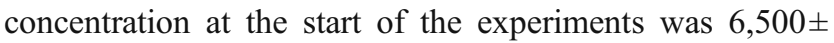
1,700 cells per milliliter. For all blank experiments, no significant change in particle concentration was found. For all sponge experiments, a clear decrease in particle concentration was seen. The total carbon taken up by the sponge was calculated by multiplying POC concentration by the clearance rate.

A POC concentration of $0.49 \mathrm{mg} \mathrm{C}$ per liter was found (see Koopmans and Wijffels 2008), which is $40.8 \mu \mathrm{mol} \mathrm{C}$ per liter. The average clearance rate was $5.63 \mathrm{~L} \mathrm{~g} \mathrm{dw}^{-1} \mathrm{~h}^{-1}$, meaning that $230 \mu \mathrm{mol} \mathrm{C} \mathrm{g} \mathrm{dw}{ }^{-1} \mathrm{~h}^{-1}$ was pumped into the sponge. For the two sponges used here, we found a constant clearance rate per gram sponge.

\section{Carbon Assimilation Rate in Biomass}

To calculate the rate of carbon incorporation into biomass, the growth rate is multiplied by the carbon content of the sponge. The average growth rate in the summer period was
0.011 per day. This value was used to calculate carbon assimilation in the individuals used in the laboratory. For the field experiments, the specific growth rates per individual reported in previous work (Koopmans and Wijffels 2008) were used in the calculations (see Table 1). The carbon content of $H$. oculata was measured to be $19.1 \pm 2.0 \%$ of the dry weight, which was used to determine the carbon assimilation rate in micromole $\mathrm{C}$ per gram $\mathrm{dw}$ per day.

\section{Carbon Dioxide Production Rate}

The carbon dioxide production rates were calculated using the respiration rates and the RQ, where an RQ of 0.75 was assumed as described in the introduction. Figure 3 shows an example of a sponge respiration measurement together with a blank measurement. The oxygen concentration during the blank measurements stayed constant, while a clear decrease was seen if a sponge was inside the chamber. The slope is the respiration rate in milligram $\mathrm{O}_{2}$ per liter per minute.

Figure 4 shows the average respiration rates for the used sponge individuals both in situ and in the laboratory. It can be seen that the respiration rate has a clear positive correlation with sponge size ( $t$ test, $p=0.000)$. In this study, a linear relation $\left(R=1.78 \mathrm{dw}-0.24\right.$, adjusted $\left.R^{2}=0.768\right)$ resulted in the best fit. The results for the carbon dioxide production rates per gram dry weight as calculated from the respiration rates are shown in Table 1.

\section{Carbon Balance}

Next, it can be calculated how much of the POC present in the water is actually metabolized by the sponge. The retention rate of POC was calculated to be $230 \mu \mathrm{mol} \mathrm{C} \mathrm{g} \mathrm{dw}{ }^{-1} \mathrm{~h}^{-1}$, which was pumped through the sponge in the form of POC. The average carbon growth rate was $7.6 \mu \mathrm{mol} \mathrm{C} \mathrm{g} \mathrm{dw}{ }^{-1} \mathrm{~h}^{-1}$, and the average carbon dioxide production rate was $70.4 \mu \mathrm{mol} \mathrm{C} \mathrm{g} \mathrm{dw}{ }^{-1} \mathrm{~h}^{-1}$ (Table 1), leading to a average total carbon demand per hour of $78.0 \mu \mathrm{mol} \mathrm{C}$. Thus, about

Table 1 Dry weight, specific growth rate, carbon assimilation rate (C growth), carbon dioxide production rate (C resp), and the net growth efficiency of six individuals of Haliclona oculata

\begin{tabular}{lccccc}
\hline Sponge & Dry weight $(\mathrm{g})$ & Growth rate (per day) & $\mathrm{C}$ growth $\left(\mu \mathrm{molg} \mathrm{dw}{ }^{-1} \mathrm{~h}^{-1}\right)$ & $\mathrm{C} \mathrm{resp}\left(\mu \mathrm{molg} \mathrm{dw}{ }^{-1} \mathrm{~h}^{-1}\right)$ & Net growth efficiency $(\mathrm{NGE})$ \\
\hline No. 1 & 0.42 & 0.0131 & 8.67 & 63.13 & 0.12 \\
No. 2 & 0.87 & 0.0125 & 8.28 & 80.15 & 0.09 \\
No. 3 & 0.77 & 0.0106 & 7.02 & 73.48 & 0.09 \\
Lab 1 & 0.64 & $0.0110^{\mathrm{a}}$ & 7.28 & 72.96 & 0.09 \\
Lab 2 & 1.10 & $0.0110^{\mathrm{a}}$ & 7.28 & 60.58 & 0.09 \\
Lab 3 & 0.86 & $0.0110^{\mathrm{a}}$ & 7.28 & 0.11 \\
\hline
\end{tabular}

Carbon assimilation and carbon dioxide production are both expressed in micromole $\mathrm{C}$ per gram dry weight per hour

${ }^{a}$ Average growth rate found for this sponge in summer 


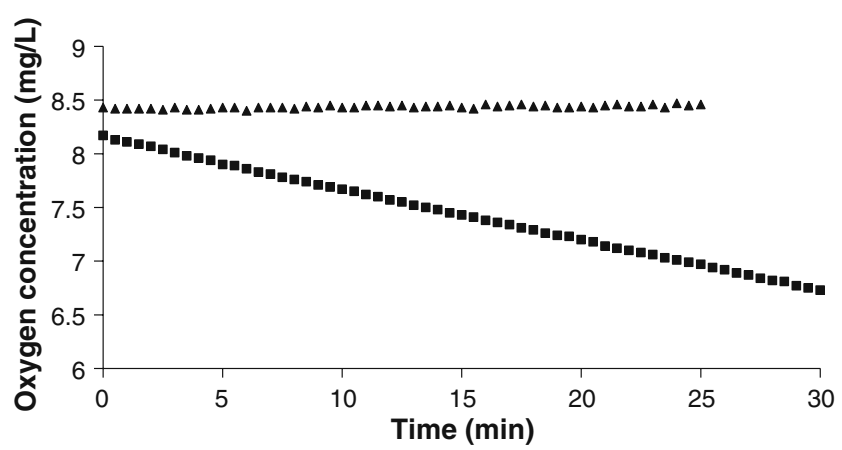

Fig. 3 The oxygen concentration inside the experimental chamber as a function of time. A blank measurement (triangles) as well as a sponge respiration measurement (squares) is shown

$34 \%$ of the carbon entering the sponge as POC was used by the sponge.

\section{Growth Efficiency}

The net growth efficiency is the ratio of carbon fixed in biomass to the total amount of carbon used by the sponge (see Eq. 1), where the total amount used is the sum of the carbon fixed in biomass and the carbon converted to carbon dioxide. Table 1 shows the net growth efficiency as calculated from Eq. 1. Net growth efficiencies found for the six individuals were in the same range with an average value of $0.099 \pm 0.013$ (average \pm standard deviation (SD)). Thus, almost $10 \%$ of the assimilated carbon is used for direct incorporation in biomass, and over $90 \%$ is used for generating energy for growth, maintenance, reproduction, and pumping.

\section{Replicate Experiments}

In our experiments, we have used three replicate sponge specimens in situ, which is the absolute minimum for

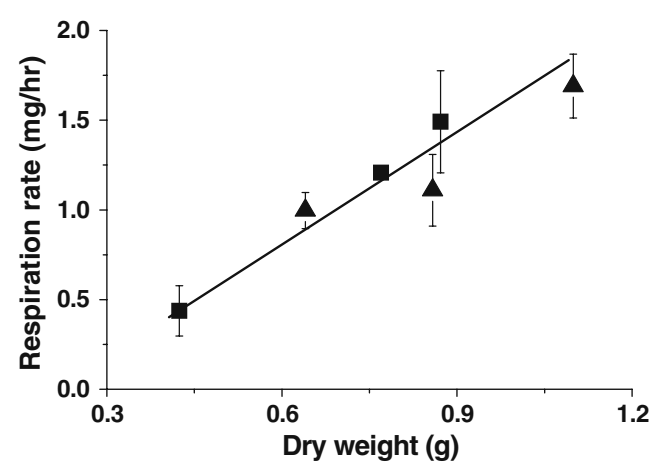

Fig. 4 Average respiration rates ( \pm standard deviation) in milligram $\mathrm{O}_{2}$ per hour related to dry weight of the sponge. The laboratory measurement (triangles) and the field measurement (squares) are shown using different symbols. The line represents the best linear regression for all experiments together experiments. We chose to have more (five) measurements spread over a limited period (4 weeks) for the three individuals, in order to obtain accurate measurements per specimen in a limited time. The variation between the three in situ individuals was low, and the respiration rate results for the laboratory individuals were close to the in situ results (Fig. 4). Based on this, we believe that using more individuals would not have altered the conclusions of this paper.

\section{Discussion}

The assumed RQ has an influence on the total carbon balance and the resulting calculations for both clearance efficiency and NGE. The RQ value can be different for different sponges and different invertebrates. A value of 0.75 is an average value found in literature for different invertebrate species. The RQ is mainly determined by the elemental composition of the food source and the type of metabolism. Keeping in mind the elemental composition of algae $\left(\mathrm{CH}_{1.6} \mathrm{O}_{0.4} \mathrm{~N}_{0.2}\right.$; Richmond 2004), a value for the RQ for sponges feeding on algae is theoretically 0.72 . Likewise, for bacteria $\left(\mathrm{CH}_{1.8} \mathrm{O}_{0.5} \mathrm{~N}_{0.2}\right.$; Roels 1983), a value of 0.85 can be calculated. If only fatty acids are used, a value of around 0.7 is obtained, which is the minimal value that can be reached. For growth on only sugars, a value of 1.0 is obtained. Since POC contains a lot of algae and sponges feed on algal cells, a value of 0.75 of the RQ seems logical. Higher values of RQ lead to a higher percentage of carbon used for respiration. The influence of RQ for the different calculations will be discussed further.

Of the available particulate carbon, $34 \%$ was used by the sponge $H$. oculata. Possible explanations for the low carbon usage are that carbon is not limiting or that not all carbon in the POC is available for consumption. Ribes et al. 1999 found that a large part of the particulate organic matter consisted of detritus and that this was not retained by Dysidea avara. Yahel et al. (2003) concluded that about $12 \%$ of the total organic carbon was removed from the water by the sponge, taking both POC and DOC into account. We have neglected the available DOC, which in our experiments was approximately three times more than the particulate carbon (Koopmans and Wijffels 2008). DOC was not taken into account, because the growth rate for H. oculata was found to have no correlation with DOC (Koopmans and Wijffels 2008). If we would take the DOC pool into account, only $9 \%$ of the available carbon is used by the sponge. Moreover, a lower RQ would result in a lower usage of the total carbon pool, for an RQ of 0.7, this would be $32 \%$. And vice versa, a higher RQ would result in a higher carbon fraction used, with an RQ of 1.0 leading to $44 \%$ carbon usage. 
The values for the respiration rate are relatively high for H. oculata (Table 2). Osinga et al. (1999) made a comparison for respiration rates of different sponges. In this study, the one Haliclona species present also had higher respiration rates, which were in the same range as found in this study. Moreover, sufficient carbon was available to cope with this high respiration rate. For calculating the clearance rate, which in turn is used to calculate the carbon uptake rate, we used a retention efficiency of $100 \%$ for the Synechococcus cells, because we found that the equation assuming $100 \%$ retention efficiency fitted the data significantly better than an equation assuming a lower efficiency. Lower retention efficiencies for Synechococcus would result in higher clearance rates and thus, in even more carbon entering the sponge. Of course, a large part of this carbon is present in other particles than Synechococcus, and these particles are not all $100 \%$ retained meaning not all carbon entering the sponge is retained. This can at least in part explain the low percentage of carbon usage as compared to the amount of carbon flowing through the sponge.

Table 2 lists the respiration rate and clearance rate and clearance efficiency per gram dry weight for different sponges. Clearance efficiency gives us the ratio between carbon uptake by the sponge and the respiration rate. We were expecting that sponges living in nutrient-rich habitats like in this study would have relatively low clearance rates, but no relation is observed between POC concentration and clearance rate for the different sponges (Table 2). Figure 5 shows the clearance efficiencies for seven sponge species. The line indicates the minimal needed RQ value of 0.75 ; otherwise not enough carbon is taken up to account for the carbon dioxide formed through respiration. Clearance efficiencies found for $H$. oculata are within the range found in literature. $H$ oculata has a clearance efficiency of 2.5 , which shows that a sufficient amount of particulate carbon is taken up to account for the high respiration rate. The same holds for Mycale sp, Tethya crypta, and D. avara. However, the bacterial sponge Verongia gigantea has a value of 0.54 , which is lower than the limit of 0.75 , suggesting insufficient carbon uptake from the particulate carbon pool. Also Halichondria panicea and Negombata magnifica show relatively low values, although still a little bit higher than the value of 0.75 . This means that these two species would need very high retention efficiencies to deal with the carbon demand.

A possible explanation for the low clearance efficiency of $V$. gigantea is that these sponges obtain carbon from the DOC pool. Reiswig (1973) concluded that the less efficient and symbiotic $V$. gigantea obtains a large part of its food requirements from the dissolved pool, which is probably done by the symbiotic bacteria. Notably, also N. magnifica and $H$. panicea contain symbiotic bacteria, although not in such high amounts as V. gigantea (Gillor et al. 2000; Althoff et al. 1998). To obtain sufficient carbon, these sponges would need very high clearance rates for which there is no evidence. Therefore, we suggest that also these sponges that contain bacteria will use the dissolved carbon pool. Moreover, symbionts in these sponges could be photosynthetic and provide the sponge with photosynthetically obtained carbon. Furthermore, the sponges in Table 2 that show values higher than 0.75 for clearance efficiency are sponges that contain none or few bacteria. Until now, it is not clear what the exact role of DOC is for sponges. It is shown that sponges can use the DOC pool (Yahel et al. 2003; de Goeij et al. 2008a). However, it is still debated if the symbionts inside sponges are responsible for the total DOC usage.

Table 2 Temperature, POC, clearance efficiency, and clearance and respiration rates for different sponge species expressed per $1 \mathrm{~g}$ of dry weight unless stated otherwise

\begin{tabular}{|c|c|c|c|c|c|c|}
\hline Species & Temperature $\left({ }^{\circ} \mathrm{C}\right)$ & $\begin{array}{l}\text { Concentration POC } \\
(\mathrm{mg} / \mathrm{l})\end{array}$ & $\begin{array}{l}\text { Clearance } \\
\text { rate }\left(\mathrm{Lh}^{-1}\right)\end{array}$ & $\begin{array}{l}\text { Respiration rate } \\
\left(\mu \mathrm{mol} \mathrm{O}_{2} \mathrm{~h}^{-1}\right)\end{array}$ & $\begin{array}{l}\text { Clearance efficiency } \\
\left(\mu \mathrm{mol} \mathrm{C} \mu \mathrm{mol} \mathrm{O}{ }_{2}^{-1}\right)\end{array}$ & Reference \\
\hline Haliclona oculata & 19 & $0.49^{\mathrm{a}}$ & 5.67 & 95.54 & 2.45 & This study \\
\hline Mycale sp & $29^{\mathrm{b}}$ & $0.064^{\mathrm{c}}$ & $12.29^{\mathrm{b}}$ & $25.26^{\mathrm{b}}$ & 2.60 & Reiswig 1974 \\
\hline Verongia gigantea & $29^{\mathrm{b}}$ & $0.064^{\mathrm{c}}$ & $2.77^{\mathrm{b}}$ & $27.39^{\mathrm{b}}$ & 0.54 & Reiswig 1974 \\
\hline Tethya crypta & $30^{\mathrm{b}}$ & $0.085^{\mathrm{c}}$ & $3.72^{\mathrm{b}}$ & $6.64^{\mathrm{b}}$ & 3.96 & Reiswig 1974 \\
\hline Halichondria panicea & 14 & 0.2 & 1.70 & 26.75 & 1.06 & $\begin{array}{r}\text { Thomassen and } \\
\text { Riisgård } 1995\end{array}$ \\
\hline Dysidea avara & 17 & 0.387 & 0.65 & 9.25 & 2.28 & Ribes 1998 \\
\hline Negombata magnifica & 22.5 & $0.048^{\mathrm{d}}$ & 4.20 & 14.88 & 1.13 & Hadas et al. 2008 \\
\hline
\end{tabular}

${ }^{\text {a }}$ Data from Koopmans and Wijffels 2008

${ }^{\mathrm{b}}$ Temperature and gram dry weight per gram ash free dry weight (g DW/g AFDW) conversion from Reiswig 1973

${ }^{\mathrm{c}}$ Values from Reiswig 1971

${ }^{\mathrm{d}}$ Personal communication 


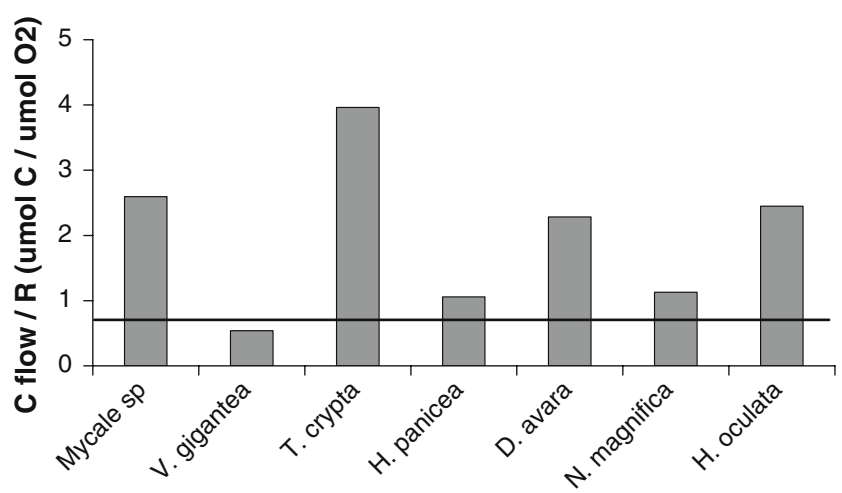

Fig. 5 Clearance efficiency for different sponge species. The line indicates the assumed minimal value for respiratory quotient of 0.75 needed for invertebrates. See Table 2 for the used references per sponge

The net growth efficiency of $H$. oculata was only $10 \%$. An RQ value lower than the assumed 0.75 would result in less carbon dioxide production and thus, in a higher NGE (for example, $\mathrm{NGE}=10.5 \%$ for $\mathrm{RQ}=0.7$ ). A higher $\mathrm{RQ}$ would result in more carbon dioxide production and thus, in even lower NGEs (for example $\mathrm{NGE}=7.6 \%$ for $\mathrm{RQ}=1.0$ ). Carbon compounds from the food source are used to build biomass and generate energy for growth and for maintenance and work. The carbon used to generate energy is converted to carbon dioxide. Assuming the amount of carbon needed to produce energy for work (pumping), reproduction, and maintenance is constant and comparable or higher than the energy needed for growth, higher growth rates will result in higher net growth efficiencies. Thomassen and Riisgård (1995) showed that NGE is indeed positively related to specific growth rate. They found for $H$. panicea that the highest growth rate of 0.04 per day related to a NGE of $30 \%$. At a growth rate of about 0.01 per day, they found a NGE of $10 \%$, similar to what we found. The experiments done here are performed in the summer, where sponge growth was measured to be higher than in other times of the year. Therefore, it can be assumed that NGE will be lower in winter and autumn. However, the energy demand for nongrowth-related processes could also be lower at lower temperatures, resulting in a higher NGE.

Thus, $90 \%$ of the carbon uptake is used to generate energy for growth and other processes like pumping, reproduction, or secondary metabolite production. Several studies have shown that suspension feeding animals are unlikely to be restricted by the energy cost of water pumping (Riisgård et al. 1993 and references within). Riisgård et al. (1993) found that the energy cost for pumping was only $0.85 \%$ of the gained energy by respiration. Up till now, not much is known about the energy demand of sponges for reproduction. It was found that other processes are ceased due to reproductive efforts. $H$. panicea decreases silica uptake during reproduction and therefore, spicule production was reduced (Frohlich and Barthel 1997). In which reproductive state, the sponges were during our experiments is not known, but it was shown that $H$. oculata in the Netherlands contains oocytes and embryos almost year round (Wapstra and van Soest 1987) and thus, reproduction seems to be an ongoing process in this sponge. Other studies have shown that sponge explants or smaller sponges show higher growth rates (e.g., Page et al. 2005, de Caralt et al. 2007). However, in our growth study, the sponge growth rate was about the same at the start and at the end, while at the beginning of the growth experiment the sponges were explants (Koopmans and Wijffels 2008).

Finally, sponges show high regeneration rates, and they continuously reform (Ayling 1983, de Caralt et al. 2007). On one side sponges can grow, while on the other they may shrink. In accordance with this, de Caralt et al. (2008) suggest that sponges have a high apoptosis rate as well as a high rate of mitoses resulting in a low net growth rate. This continuous regeneration of sponge tissue will cost a lot of energy, while low net growth is obtained.

Benthic filter feeders in general typically show oxygen extraction coefficients up to $10 \%$ (Jorgensen et al. 1986). For $H$. oculata we found the oxygen extraction coefficient to be $3.3 \%$. Thus, oxygen clearly does not limit sponge growth rate under normal conditions. Carbon availability seems to be sufficient as well, although we do not know exactly what part of the particulate carbon is usable by the sponge. The NGE agrees with the low growth rates found for this sponge species, since at low growth rates a relatively large part of carbon taken up is used for generating energy for maintenance and work.

In conclusion, oxygen and probably also carbon are not limiting the growth rate of $H$. oculata. First of all, it should be established whether $H$. oculata is able to grow faster or whether the growth rate observed here is the maximum value this sponge can reach. For example, there are indications that sponges are continuously remodeling in other words grow fast and at the same time break down biomass. Furthermore, more insight in sponge metabolism could also give indications on possible limitations. Both goals can be reached by using labeled substrates and follow the metabolic pathway through which they are metabolized and the rate at which this occurs. Knowledge on sponge metabolism and growth in situ, may also give indications on why it is so difficult to grow sponges outside their natural habitat in aquaria, which is a prerequisite for sustainable production. 


\section{Conclusion}

Respiration rate, clearance rate, and growth rate have been measured for the sponge $H$. oculata. We found that only $34 \%$ of the available particulate carbon is used by the sponge for both respiration and growth. $H$. oculata appears not to be carbon limited. Sufficient carbon is available in the particulate pool for $H$. oculata as the respiratory carbon requirement can be easily fulfilled with the taken up particulate carbon. The net growth efficiency, being the ratio of carbon assimilated in biomass and the total carbon used by the sponge, was found to be $0.099 \pm 0.013$ (average \pm SD). Thus, only about $10 \%$ of the assimilated carbon is fixed in biomass, and over $90 \%$ is used for generating energy for growth, maintenance, pumping, and reproduction. The low NGE agrees with the low growth rates found for this sponge species. Oxygen was found not to be the limiting factor for growth, since only $3.3 \%$ of the oxygen pumped through the sponge body was used.

Acknowledgments This study was funded by NWO-ALW (814.02.010). We thank the Waterboard Zeeuwse Eilanden and the Province of Zeeland for issuing the necessary permits. We thank H. de Rooij and colleagues of the Technical Workshop of Wageningen University for making the experimental chambers. We are grateful to A. Kliphuis, P. Lamers, J. Lindenbergh, B. van Vark, and E. van Vark for their help with placing the platform. J. Bergervoet is thanked for his help with the flow cytometer analysis and F. van de End for his help keeping the aquaria up to date with the changing environment in the field.

Open Access This article is distributed under the terms of the Creative Commons Attribution Noncommercial License which permits any noncommercial use, distribution, and reproduction in any medium, provided the original author(s) and source are credited.

\section{References}

Althoff K, Schütt C, Steffen R, Batel R, Müller WEG (1998) Evidence for a symbiosis between bacteria of the genus Rhodobacter and the marine sponge Halichondria panicea: harbor also for putatively toxic bacteria? Mar Biol 130:529-536

Ayling AL (1983) Growth and regeneration rates in thinly encrusting demospongiae from temperate waters. Biol Bull 165:343-352

Barthel D (1986) On the ecophysiology of the sponge Halichondria panicea in Kiel Bight. I. Substrate specificity, growth and reproduction. Mar Ecol Progr Ser 32:291-298

Boucher-Rodoni R, Boucher G (1993) Respiratory quotient and calcification of Nautilus macromphalus (Cephalopoda: Nautiloidea). Mar Biol 117:629-633

Collyer DM, Fogg GE (1954) Studies on fat accumulation by algae. J Exp Bot 6(17):256-275

Dayton PK (1979) Observations of growth, dispersal and population dynamics of some sponges in McMurdo Sound, Antarctica. Colloques Internationaux du C.N.R.S. 291:271-282

De Caralt S, Uriz MJ, Wijffels RH (2007) Grazing, differential size-class and survival of a Mediterranean sponge species: Corticium candelabrum. Mar Ecol Prog Ser 360:97-106

De Caralt S, Uriz MJ, Wijffels RH (2008) Cell culture from sponges: pluripotency and immortality. Trends Biotech 25(10):467-471
De Goeij JM, van den Berg H, van Oostveen MM, Epping EHG, van Duyl FC (2008a) Major bulk dissolved organic carbon (DOC) removal by encrusting coral reef cavities sponges. Mar Ecol Prog Ser 357:139-151

De Goeij JM, Moodley L, Houtekamer M, Carballeira NM, van Duyl FC (2008b) Tracing ${ }^{13} \mathrm{C}$-enriched dissolved and particulate organic carbon in the bacteria containing coral reef sponge Halisarca caerulea: evidence for DOM feeding. Limnol Oceanogr 53 (4):1376-1386

Duckworth AR, Pomponi SA (2005) Relative importance of bacteria, microalgae and yeast for growth of the demospongiae Halichondria melanadocia. J Exp Mar Biol Ecol 323:151-159

Duckworth AR, Samples GA, Wright AE, Pomponi SA (2003) In vitro culture of the tropical sponge Axinella corrugata (Demospongiae): effect of food cell concentration on growth, clearance rate and biosynthesis of stevensine. Mar. Biotechnol. 5:519-527

Duckworth AR, Brück WM, Janda KE, Pitts TP, McCarthy PJ (2006) Retention efficiencies of the coral reef sponges Aplysina lacunosa, Callyspongia vaginalis and Niphates digitalis determined by Coulter counter and plate culture analysis. Mar Biol Res 2 (4):243-248

Frohlich H, Barthel D (1997) Silica uptake of the marine sponge Halichondria panicea in Kiel Bight. Mar Biol 128:115-125

Garrabou J, Zabala M (2001) Growth dynamics in four Mediterranean demosponges. Estuar Coast Shelf Sci 52:293-303

Gillor O, Carmeli S, Rahamim Y, Fishelson Z, Ilan M (2000) Immunolocalization of the toxin latrunculin B within the Red Sea sponge Negombata magnifica (Demospongiae, Latruncullidae). Mar Biot 2:213-223

Hadas E, Ilan M, Sphigel M (2008) Oxygen consumption by a coral reef sponge. J Exp Biol 211:2185-2190

Hatcher A (1989) RQ of benthic marine invertebrates. Mar Biol 102:445-452

Hu Q, Sommerfeld M, Jarcis E, Ghirardi M, Posewitz M, Seibert M, Darzins A (2008) Microalgal triacylglycerols as feedstocks for biofuels production: perspectives and advances. Plant J 54:621639

Jorgensen CB, Møhlenberg F, Sten-Knudsen O (1986) Nature of relation between ventilation and oxygen consumption in filter feeders. Mar Ecol Prog Ser 29:73-88

Koopmans M, Wijffels RH (2008) Seasonal growth rate of the sponge Haliclona oculata (Demospongiae: Haplosclerida). Mar Biot 10:502-510

Lynch TC, Phlips EJ (2000) Filtration of the bloom-forming cyanobacteria Synechococcus by three sponge species for Florida Bay, U.S.A. Bull Mar Sci 67(3):923-936

Migné A, Davoult D (1997) Carbon dioxide production and metabolic parameters in the ophiurid Ophiothrix fragilis. Mar Biol 127:699-704

Mohlenberg F, Riisgard HU (1978) Efficiency of particle retention in 13 species of suspension feeding bivalves. Ophelia 17(2):239 246

Moreira-Turcq PF, Martin JM (1998) Characterization of fine particles by flow cytometry in estuarine and coastal Arctic waters. J Sea Res 39:217-227

Nieuwenhuize J, Maas YEM, Middelburg JJ (1994) Rapid analysis of organic carbon and nitrogen in particulate materials. Mar Chem $45: 217-224$

Osinga R, Tramper JJ, Wijffels RH (1999) Cultivation of marine sponges. Mar Biot 1:509-532

Page MJ, Northcote PT, Webb VL, Mackey S, Handley SJ (2005) Aquaculture trials for the production of biologically active metabolites in the New Zealand sponge Mycale hentscheli (Demospongiae: Poecilosclerida). Aquaculture 250:256-269

Pile AJ, Patterson MR, Savarese M, Chernykh VI, Fialkov VA (1997) Trophic effects of sponge feeding within Lake Baikal's littoral 
zone. 2. Sponge abundance, diet, feeding efficiency, and carbon flux. Limnol Oceanogr 42(1):178-184

Reiswig HM (1971) Particle feeding in natural populations of three marine demosponges. Biol Bull 141:568-591

Reiswig HM (1973) Population dynamics of three Jamaican Demospongiae. Bull Mar Sci 23(2):191-226

Reiswig HM (1974) Water transport, respiration and energetics of three tropical marine sponges. J Exp Mar Biol Ecol 14:231-249

Ribes M (1998) Feeding activity and diet of benthic suspension feeders related to metabolic requirements and seston composition. $\mathrm{PhD}$ dissertation, University of Barcelona, Barcelona, Spain

Ribes M, Coma R, Gili JM (1999) Natural diet and grazing rate of the temperate sponge Dysidea avara (Demospongiae, Dendroceratida) throughout an annual cycle. Mar Ecol Prog Ser 176:179-190

Richmond A (2004) Handbook of microalgal culture. Biotechnology and Applied Phycology. ISBN 0-632-05953-2

Riisgård HU, Thomassen S, Jakobsen H, Weeks JM, Larsen PS (1993) Suspension feeding in marine sponges Halichondria panicea and
Haliclona urceolus: effects of temperature on filtration rate and energy cost of pumping. Mar Ecol Prog Ser 96:177-188

Roels JA (1983) Energetics and kinetics in biotechnology. Elsevier Biomedical Press, Amsterdam

Stabili L, Licciano M, Giangrande A, Longa C, Mercurio M, Marzano CN, Corriero G (2006) Filtering activity of Spongia officinalis var. Adriatical (Schmidt) (Porifera, Demospongiae) on bacterioplankton: Implications for bioremediation of polluted seawater. Water Res 40:3083-3090

Thomassen S, Riisgård HU (1995) Growth and energetics of the sponge Halichondria panicea. Mar Ecol Prog Ser 128:239-246

Wapstra M, van Soest RWM (1987) Sexual reproduction, larval morphology and behaviour in demosponges from the southwest of the Netherlands. Taxonomy of Porifera, NATO ASI Ser G13:281-307

Yahel G, Sharp JH, Marie D, Häse C, Genin A (2003) In situ feeding and element removal in the symbiont-bearing sponge Theonella swinhoei: bulk DOC is the major source of carbon. Limnol Oceanogr 48:141-149 